\title{
Quasi-Static and Dynamic Compressive Behavior of Gum Metal: Experiment and Constitutive Model
}

\author{
KAROL MAREK GOLASIŃSKI, JACEK JANISZEWSKI, JUDYTA SIENKIEWICZ, \\ TOMASZ PŁOCIŃSKI, MACIEJ ZUBKO, PAWEŁ ŚWIEC, \\ and ELŻBIETA ALICJA PIECZYSKA
}

The quasi-static and high strain rate compressive behavior of Gum Metal with composition Ti-36Nb-2Ta-3Zr-0.3O (wt pct) has been investigated using an electromechanical testing machine and a split Hopkinson pressure bar, respectively. The stress-strain curves obtained for Gum Metal tested under monotonic and dynamic loadings revealed a strain-softening effect which intensified with increasing strain rate. Moreover, the plastic flow stress was observed to increase for both static and dynamic loading conditions with increasing strain rate. The microstructural characterization of the tested Gum Metal specimens showed particular deformation mechanisms regulating the phenomena of strain hardening and strain softening, namely an adiabatic shear band formed at $\sim 45 \mathrm{deg}$ with respect to the loading direction as well as widely spaced deformation bands (kink bands). Dislocations within the channels intersecting with twins may cause strain hardening while recrystallized grains and kink bands with crystal rotation inside the grains may lead to strain softening. A constitutive description of the compressive behavior of Gum Metal was proposed using a modified Johnson-Cook model. Good agreement between the experimental and the numerical data obtained in the work was achieved.

https://doi.org/10.1007/s11661-021-06409-z

(C) The Author(s) 2021

\section{INTRODUCTION}

HigH-STRENGTH construction materials, available on the market, usually do not possess good elastic properties. In turn, elastic materials usually have low strength parameters. However, at the turn of the century, unique Ti-based alloys that combine high strength with excellent elasticity, named Gum Metals, were designed. The name Gum Metal stands for a group of multifunctional $\beta$-Ti alloys, which were developed by the Toyota Central Research and Development

KAROL MAREK GOLASIŃSKI and ELŻBIETA ALICJA PIECZYSKA are with the Institute of Fundamental Technological Research, Polish Academy of Sciences, Pawińskiego 5B, 02-106, Warsaw, Poland. Contact-email: kgolasin@ippt.pan.pl JACEK JANISZEWSKI and JUDYTA SIENKIEWICZ are with the Faculty of Mechatronics, Armament and Aerospace, Military University of Technology, Kaliskiego 2, 00-908 Warsaw, Poland. TOMASZ PŁOCINSKI is with the Faculty of Materials Science and Engineering, Warsaw University of Technology, Wołoska 141, 02-507 Warsaw, Poland. MACIEJ ZUBKO is with the Institute of Materials Engineering, University of Silesia, 75 Pułku Piechoty 1A, 41-500, Chorzów, Poland and also with the Department of Physics, Faculty of Science, University of Hradec Králové, Rokitanského 62, 500 03, Hradec Králové, Czech Republic. PAWEŁ ŚWIEC is with the Institute of Materials Engineering, University of Silesia.

Manuscript submitted October 12, 2020; accepted July 19, 2021

Article published online August 11, 2021
Laboratories at the beginning of the twenty-first century. ${ }^{[1]}$ The typical composition of Gum Metal is Ti-36Nb-2Ta-3Zr-0.3O (in wt pct). The fabrication process including cold working and the role of oxygen in the composition are critical for the unique mechanical performance of the alloy, i.e. low Young's modulus, relatively large nonlinear recoverable deformation, good ductility and high strength. ${ }^{[2,3]}$ The mechanical properties combined with the nontoxic and nonallergic chemical composition of Gum Metal make it a promising candidate for orthopedic and dental implants. ${ }^{[4-6]}$ Conventional Ti-based materials used in the medical industry, such as pure titanium or Ti-6Al-4V, are characterized by a relatively high Young's modulus $(>100 \mathrm{GPa})$ which is over five times higher compared to that of a human bone. ${ }^{[4]}$ Moreover, aluminum is considered a factor causing Alzheimer's disease, and the content of vanadium can be toxic. ${ }^{[7,8]}$ Initially, the mechanism of the superelastic-like behavior of Gum Metal was not fully understood. The oxygen content in the alloy after the process of cold working was said to hinder the martensitic transformation. ${ }^{[2]}$ In, ${ }^{[9]}$ microstructures of oxygen-added cold worked $\beta$-Ti-Nb alloys were studied using in situ X-ray diffraction measurements and in situ TEM observations. It was found that nanosized modulated domains (nanodomains) of the $\alpha^{\prime \prime}$ phase in the $\beta$ phase act as local 
barriers to martensitic transformation, thereby suppressing long-range martensitic transformation in this class of alloys. The nanodomain structure was also studied in. ${ }^{[10,11]}$ This unconventional deformation mechanism was also investigated by analyzing the mean thermal response of Gum Metal under loading using infrared thermography. ${ }^{[12-14]}$ In, ${ }^{[13]}$ it was shown that a drop in temperature during loading, related to the thermoelastic effect, is also followed by a temperature rise within the recoverable strain of the alloy. In other words, it was demonstrated that the large nonlinear recoverable deformation of Gum Metal is a dissipative process. This means that the underlying deformation mechanism is different from the classical elastic stretches of atomic bonding. The findings were confirmed and broadened by a comprehensive investigation realized using infrared thermography in. ${ }^{[14]}$

The peculiarities of the plastic behavior of Gum Metal were initially attributed to the hypothesis of dislocation-free plastic deformation, ${ }^{[1]}$ since the ideal strength of Gum Metal calculated based on density functional theory in ${ }^{[15]}$ was in the order of the alloy tensile strength measured experimentally as shown in. ${ }^{[3]}$ Microstructure characterization of Gum Metal found distinct surface steps called "giant faults," plastic flow localization and "nanodisturbances".[16] Observations performed by high-resolution transmission electron microscopy revealed nanoprecipitates of the hexagonal $\omega$ phase in Gum Metal. ${ }^{[17-20]}$ The deformation mechanisms of Gum Metal plasticity, including the activity of dislocations, ${ }^{[21]}$ dislocation channeling and stress-induced $\omega-\beta$ transformation, ${ }^{[22]}$ as well as the mechanism of twinning, ${ }^{[23]}$ were investigated. A more detailed study demonstrated that the effective trapping of dislocations in Gum Metal is related to the average spacing of the nanometer-sized $\omega$ phase (around $6 \mathrm{~nm}$ ). ${ }^{[17]}$

Understanding of the mechanical characteristics of Gum Metal subjected to loading under various conditions is critical for its application in a variety of engineering solutions. In particular, a good material for implant applications must posses reliable characteristics under quasi-static and dynamic loadings. The strain rate sensitivity of Gum Metal under quasi-static tension using digital image correlation was already investigated in ${ }^{[24]}$ and modeled in. ${ }^{[25]}$ Anisotropy of Gum Metal was experimentally studied in. ${ }^{[26]}$ In general, the mechanical behavior of many materials during dynamic loading differs significantly from that under quasi-static conditions. Recently, investigation of the mechanical performance of advanced materials, in particular Ti-based alloys, at high strain rates has attracted increasing attention due to high reliability industrial applications, e.g., in biomedical components, crash-absorbing components, high-speed machining, military equipment, etc. The experimental investigation of the high strain rate mechanical response of $\alpha$-titanium complete with modeling was given in. ${ }^{[27]}$ The mechanical performance of an ultrafine-grained Ti-6Al-4V alloy under compression at quasi-static and high strain rates was discussed in. ${ }^{[28]}$ Adiabatic shear localization in a metastable beta titanium alloy deformed at high strain rates and elevated temperatures was characterized in. ${ }^{[29]}$
The mechanical behavior of Gum Metal at a high strain rate is of special interest in view of its unconventional deformation mechanisms and the related outstanding characteristics, which make it suitable for implant applications. So far, this issue has been seldom reported in the literature. Both experimental and numerical investigations are scarce. In ${ }^{[30]}$ the mechanical behavior of the extruded Gum Metal and the alloy processed by equal channel angular pressing (ECAP) was investigated under compression at various strain rates.

However, the goal of this work is to examine the compressive behavior of Gum Metal under quasi-static and dynamic loadings including analysis of microstructural changes and constitutive modeling.

\section{EXPERIMENTAL METHOD}

A Gum Metal rod of $700 \mathrm{~mm}$ length and $10 \mathrm{~mm}$ diameter with nominal composition Ti-36Nb-2Ta-3Zr-0.3O (in wt pet) was obtained using a powder metallurgical method that consisted of cold isostatic pressing, sintering at $1300{ }^{\circ} \mathrm{C}$ for 16 hours in a vacuum of $10^{-4} \mathrm{~Pa}$, hot forging and solution treatment at $900{ }^{\circ} \mathrm{C}$ for 30 minutes with final quenching in iced water. The bar was cold worked with a rotary swaging machine to obtain a 90 pct reduction in area. Cylindrical samples of $5 \mathrm{~mm}$ length and $5 \mathrm{~mm}$ diameter for compression loadings were made from the Gum Metal rod using electrical discharge machining.

An MTS Criterion C45 electromechanical universal testing machine was used to measure the quasi-static behavior under uniaxial compression at strain rates $0.001 \mathrm{~s}^{-1}$ and $1 \mathrm{~s}^{-1}$. Grip platens made of tungsten carbide with polished contact surfaces were used. Additionally, a lubricant composed of mineral oil, lithium soap and molybdenum disulfide $\left(\mathrm{MoS}_{2}\right)$ was applied between the contact surfaces of the specimen platens to mitigate the barreling effect during the plastic deformation process.

High strain rate compression tests were performed using the classical split Hopkinson pressure bar (SHPB) technique. ${ }^{[31,32]}$ The basic parameters of the bar system shown in Figure 1 are as follows: input and output bar $1200 \mathrm{~mm}$ long; striker bar $250 \mathrm{~mm}$ long; all bars $12 \mathrm{~mm}$ in diameter. The bars were made of maraging steel (yield strength-2300 MPa; elastic wave speed-4960 $\mathrm{ms}^{-1}$ ). The striker bar was also made of the maraging steel and was driven by a compressed air system with a barrel length and inner diameter of $1200 \mathrm{~mm}$ and $12.1 \mathrm{~mm}$, respectively. The impact striker bar velocities applied during the experiments were in the range of between 10 and $24 \mathrm{~ms}^{-1}$, which ensure strain rates between 870 and $2270 \mathrm{~s}^{-1}$ for the specified size of specimens used.

The plastic flow stress and strain and strain rates of the specimen were determined according to the classical Kolsky theory ${ }^{[31]}$ using the one-wave analysis method, which assumes stress equilibrium for the specimen under the given test conditions. To minimize the wave dispersion by damping the Pochhammer-Chree 


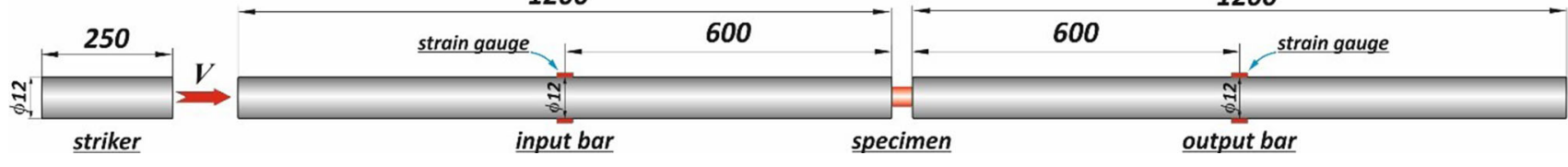

Fig. 1.- Scheme of the SHPB setup.

high-frequency oscillations and to facilitate stress equilibrium, the pulse shaping technique was used. ${ }^{[32]}$ The pulse shaper size was chosen for the given striker impact velocity and mechanical response of the tested material. It was found that for a given SHPB test condition, a copper pulse shaper with a $3-\mathrm{mm}$ diameter and thicknesses ranging from 0.1 to $0.4 \mathrm{~mm}$ (depending on the veolocity of the impact striker) guarantees damping of the high-frequency oscillations and achieving dynamic stress equilibrium in the specimen. Similarly to the quasi-static test, a grease based on $\mathrm{MoS}_{2}$ was applied to the interfaces between the specimen and the bars to minimize the interfacial friction.

Microscopic evaluation was realized using both a Phenom ProX $/ \mathrm{CeB}_{6}$ scanning electron microscope (SEM) with an acceleration voltage of $15 \mathrm{kV}$ and a KEYENCE VHX-6000 digital microscope equipped with a polarization filter allowing identification of the optically anisotropic materials. Before microscopic observations of the Gum Metal, samples were sectioned, mounted in epoxy resin and metallographically grounded and polished using silicon carbide abrasive paper and a diamond suspension $(9.3$ and $1 \mu \mathrm{m})$. Final polishing was carried out using a silica suspension of $0.1 \mu \mathrm{m}$. To reveal the microstructure, the samples were etched using Kroll's reagent $\left(20 \mathrm{~mL} \mathrm{H}_{2} \mathrm{O}+4 \mathrm{~mL}\right.$ $\mathrm{NHO}_{3}+1 \mathrm{~mL} \mathrm{HF}$ ).

SEM observations were also performed on a Hitachi SU8000 instrument (made in Naka, Japan). This microscope is equipped with a cold field emission gun (C-FEG) and can offer a greater beam current at a voltage of $5 \mathrm{kV}$. The orientation contrast images were taken by using a photo diode backscattered electron (PDBSE) detector. The images with a special orientation contrast were obtained on a stress-free surface of the sample. A cross section of the sample was prepared with a broad argon ion beam on a Hitachi IM4000 instrument (made in Naka, Japan). The EBSD analysis was performed on a Hitachi SU 70 SEM (made in Naka, Japan) at an accelerating voltage of $30 \mathrm{kV}$. This microscope was equipped with a Shottky emitter, which can provide a probe current suitable for analytical purposes. The orientation analysis was done by using an EBSD system made by HKLTechnology (made in Denmark).

The X-ray powder diffraction (XRD) measurements were carried out using a Malvern Panalytical (Malvern Instruments, Malvern, UK) Empyrean diffractometer with a $\mathrm{Cu}$ anode with a wavelength of $1.54056 \AA$ working at an electric current of $30 \mathrm{~mA}$ and a voltage of $40 \mathrm{kV}$ and equipped with a PIXcell ${ }^{3 \mathrm{D}}$ solid-state hybrid pixel detector. The XRD patterns were collected in the angular range of $2 \theta=10 \mathrm{deg}$ to $145 \mathrm{deg}$ in $0.02^{\circ}$ steps.

\section{RESULTS AND DISCUSSION}

\section{A. Quasi-Static and Dynamic Stress-Strain Response}

The true stress-strain curves of Gum Metal at quasi-static strain rates and high strain rates ranges are shown in Figures 2(a) and (b), respectively. During quasi-static loading, the tested alloy exhibits a slight difference in mechanical properties depending on the applied strain rate. At a strain rate of $0.001 \mathrm{~s}^{-1}$, the stress-strain curve shows a low slope for the plastic deformation range, which indicates a low strain hardening of Gum Metal, whereas it reveals slightly negative strain-hardening ratio at a strain rate of $1 \mathrm{~s}^{-1}$. Such mechanical behavior, which in the literature is often called strain softening, has been already reported for both Gum Metal quasi-static tensile and compression loading test conditions. ${ }^{[24,30,33]}$

It is very interesting from a cognitive point of view that a strain-softening effect intensifies with increasing strain rate. The true stress-strain curves obtained from the SHPB experiments collected in Figure 2(b) very clearly indicate a strain-softening mechanism governing the plastic deformation of the tested Gum Metal alloy. At significantly higher strain rates, the phenomenon of strain-softening is present for each of the dynamic strain rates. Moreover, it can be seen that with the increase of strain rate, the plastic flow stress increases for both static and dynamic loading conditions. The peak flow stresses are in the range between 1200 and $1400 \mathrm{MPa}$. This evidences the relatively high strain rate sensitivity of Gum Metal; however, the flow stress at the strain rates range of the SHPB experiments is mildly sensitive to the strain rate. It is also observed that the relationship between flow stress and logarithmic strain rate is not linear, and flow stress tends to increase with a strain rate $>10^{3} \mathrm{~s}^{-1}$, as shown in Figure 3(a). In turn, according to Figure 3(b), the strain rate sensitivity $m$ distinctly decreases with increasing strain. The strain rate sensitivity $m$ for the tested Gum Metal was expressed by the commonly used formula Eq. [1]:

$$
\mathrm{m}=\log \left(\sigma_{2}-\sigma_{1}\right) / \log \left(\dot{\varepsilon}_{2} / \dot{\varepsilon}_{1}\right)
$$

where stresses $\sigma_{1}$ and $\sigma_{2}$ are obtained from experiments performed at average strain rates of $\dot{\varepsilon}_{1}$ and $\dot{\varepsilon}_{2}$, respectively.

The oscillations visible in the curve for the highest strain rate applied $\left(\dot{\varepsilon}=2270 \mathrm{~s}^{-1}\right)$ are not the real mechanical response of the material, but result from the technical limitations of the SHPB technique. However, stress-strain curve oscillations were significantly reduced by applying a pulse shaper technique, and in the case of the SHPB experiments with lower strain rates, 


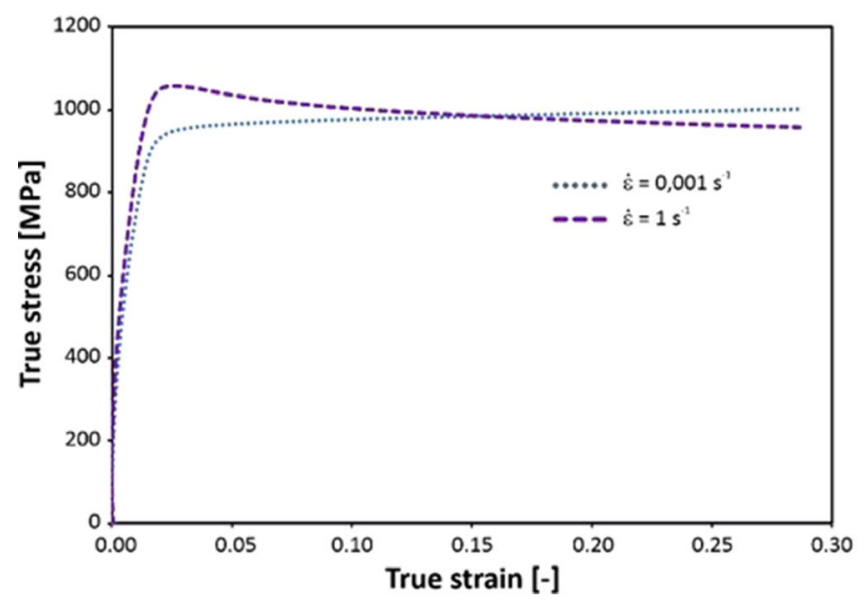

(a)

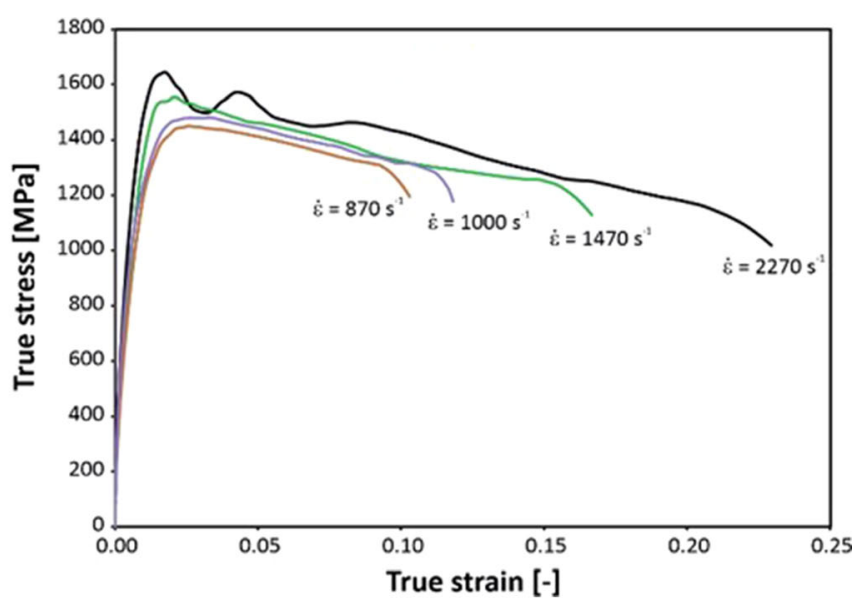

(b)

Fig. 2.-True stress vs. strain curves of Gum Metal at selected strain rates under (a) quasi-static and (b) dynamic compression.

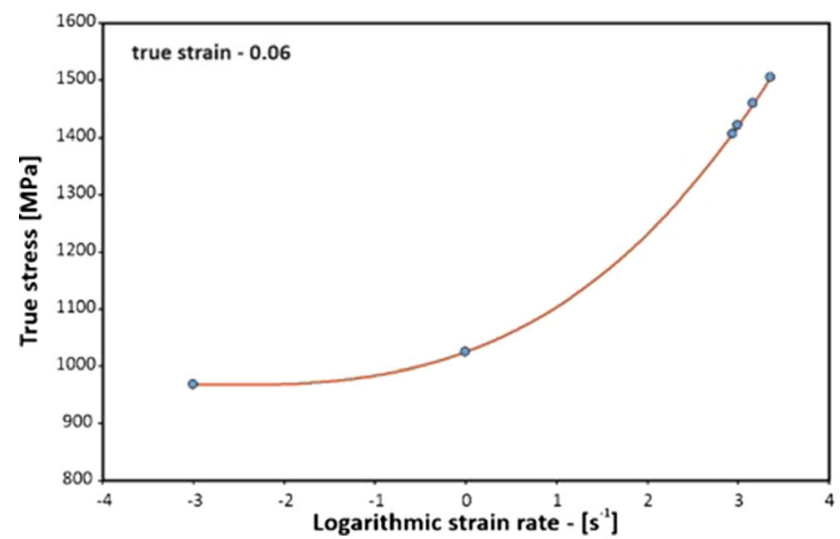

(a)

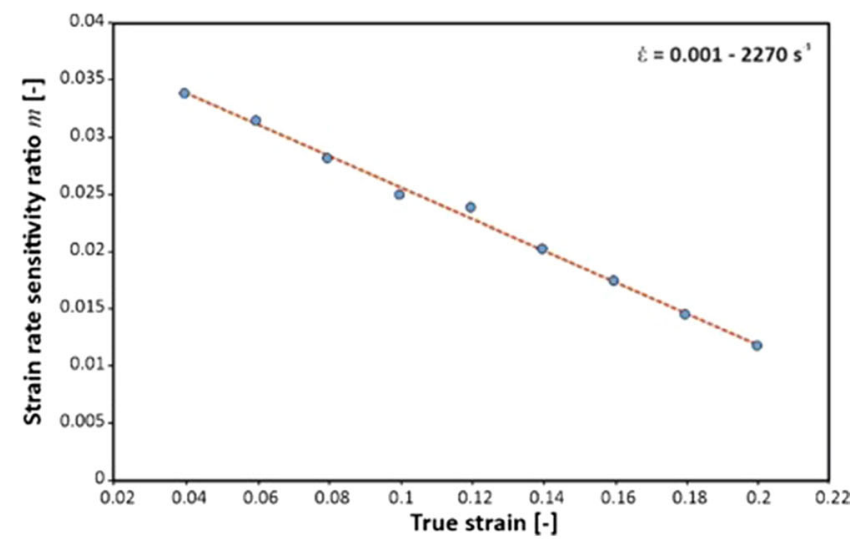

(b)

Fig. 3.- (a) Flow stress for a strain of 0.06 at different strain rates and (b) strain rate sensitivity for strain rates between 0.001 and $2270 \mathrm{~s}^{-1}$.

the obtained stress-strain curves are smooth, almost without oscillation. In addition, none of the tested specimens were damaged under dynamic loading; hence, the ends of the stress-strain curves represent the unloading stage of the specimen. An exception here is the test conducted at a strain rate of $2270 \mathrm{~s}^{-1}$. Admittedly, there was no characteristic peak on the reflected wave profile indicating a crack in the specimen, but postmortem observations of the specimen revealed a crack that probably occurred at the end of the unloading stage. The results of the metallographic study on this experimental case will be presented in the next section.

\section{B. Microstructural Characterization of Gum Metal After Compression at Selected Strain Rates}

The optical micrographs, shown in Figures 4(a) and (b), reveal that Gum Metal in its initial state is composed to some extent of equiaxed $\beta$ grains with sizes $<100 \mu \mathrm{m}$. Additionally, in the coarse grains, a number of so-called "kink bands" bands were observed as presented in Figure 4(a). A few thick distorted laths crossing the original $\beta$ grains were also found, as shown in Figure 4(b). The literature analysis indicated that similar features were noticed in a solution-treated Ti-22.4Nb-0.73Ta-2Zr-1.34O alloy. ${ }^{[34]} \mathrm{At}$ this point, it should be mentioned that in metastable $\beta$-Ti alloys such thick laths are deformation twins whereas thin lines are slip lines or stress-induced $\alpha$ " martensite. Furthermore, a so-called "marble-like" structure is observed. The literature reports that such a characteristic structure is composed of assemblies of fine filamentary structures developed by aggregation of the giant planar faults during plastic deformation. ${ }^{[1,2,35]}$ The abovementioned fractal, layered structure with a discrete strain field and a crystal lattice curved to a considerable extent results in unusual properties that are entirely different from those of other metallic materials. ${ }^{[36]}$

The microstructure of Gum Metal after quasi-static loading at a strain rate $0.001 \mathrm{~s}^{-1}$ is shown in Figures 5(a) and (b). The deformed structures formed during quasi-static testing are distributed between the equiaxed grains that were observed in the microstructure of Gum Metal in its initial state (see Figure 4). It has been also established that the deformed grains are of a 
wide range of sizes from several microns to tens of microns. It may be stated that the observed structure of the quasi-statically tested Gum Metal is evidence of further deformation from the initial state (after deformation obtained by the rotation swaging machine), and stress distribution becomes more inhomogeneous. ${ }^{[30]}$ In particular, some grains were split into smaller ones with a broad size distribution. Moreover, the number of visible parallel thin lines is reduced compared to the initial state, which is in line with the findings published in. ${ }^{[34]}$

The microstructure of Gum Metal after dynamic loading at a strain rate of $2100 \mathrm{~s}^{-1}$ is revealed in Figures 6(a) and (b). This shows similar features to the ones obtained after quasi-static loading. Apart from the presence of fragmented grains, examination of the morphology of the dynamic-loading surface shows the occurrence of some pores (Figure 6(a)).

A selected region of Gum Metal after dynamic compression at a strain rate of $2100 \mathrm{~s}^{-1}$ and its EBSD crystallographic orientation map are presented in Figures 7(a) and (b). It is clearly seen that a green color dominates in the areas of crushed grains, indicating that high dislocation density leads to severe misorientation. This was noticed in studies published in, ${ }^{[37]}$

EBSD pole figures of Gum Metal after dynamic compression at a strain rate of $2100 \mathrm{~s}^{-1}$ are shown in Figure 8 . The results show that the material exhibits a strong texture, with the $\{110\}$ crystallographic axes of the grains aligned to the swaging direction.

SEM images of Gum Metal after a Hopkinson test at a strain rate of $2270 \mathrm{~s}^{-1}$ are presented in Figure 9 (in these micrographs the loading direction is vertical). Particular areas of the micrographs were selected for a deeper analysis as presented in Figures 9(a) through (d).

It was noticed that equiaxed grains, observed in the initial state, are deformed after dynamic testing and are elongated in a direction perpendicular to the deformation direction. A fully developed adiabatic shear band (ASB) with a crack inside formed at roughly $\sim 45 \mathrm{deg}$ with respect to the loading direction indicating the maximum shear stress plane. The width of the shear band is about $\sim 50 \mu \mathrm{m}$. Within the ASB, a structure composed of ultrafine equiaxed grains is observed. Such remarkable grain refinement taking place suggests a significant temperature rise occurred during dynamic loading. ${ }^{[30]}$ It
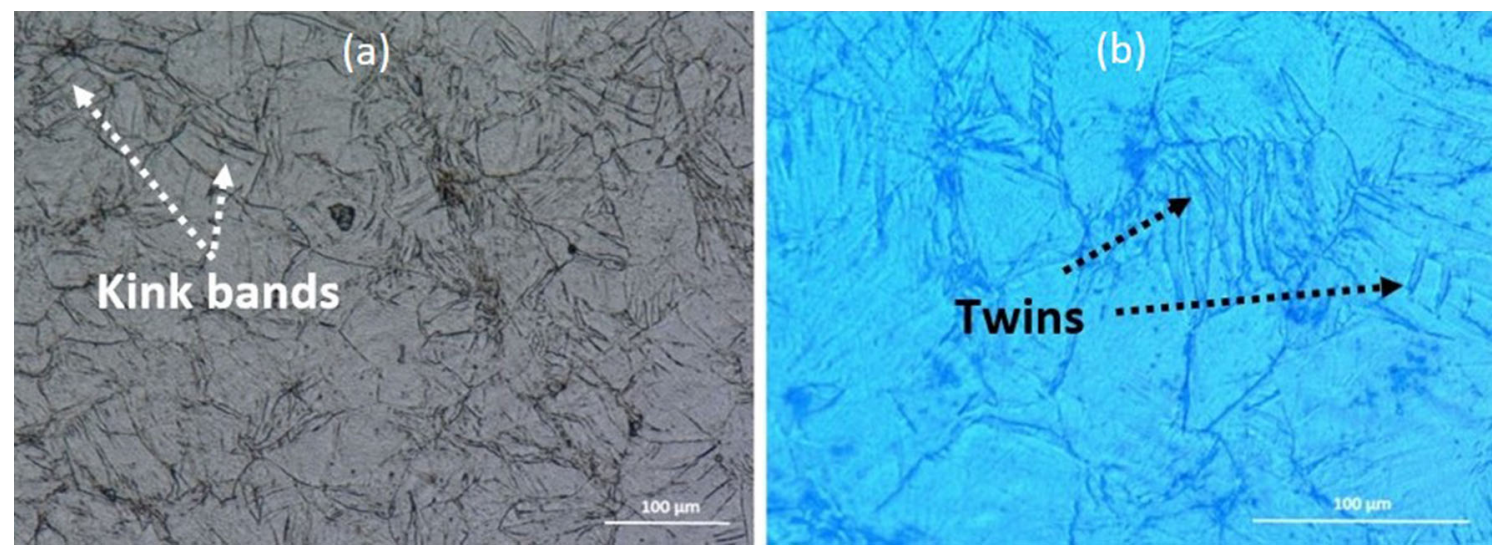

Fig. 4.-Optical micrographs of the as-received Gum Metal taken in two zones indicating: $(a)$ kink bands and $(b)$ twins obtained using a KEYENCE VHX-6000.
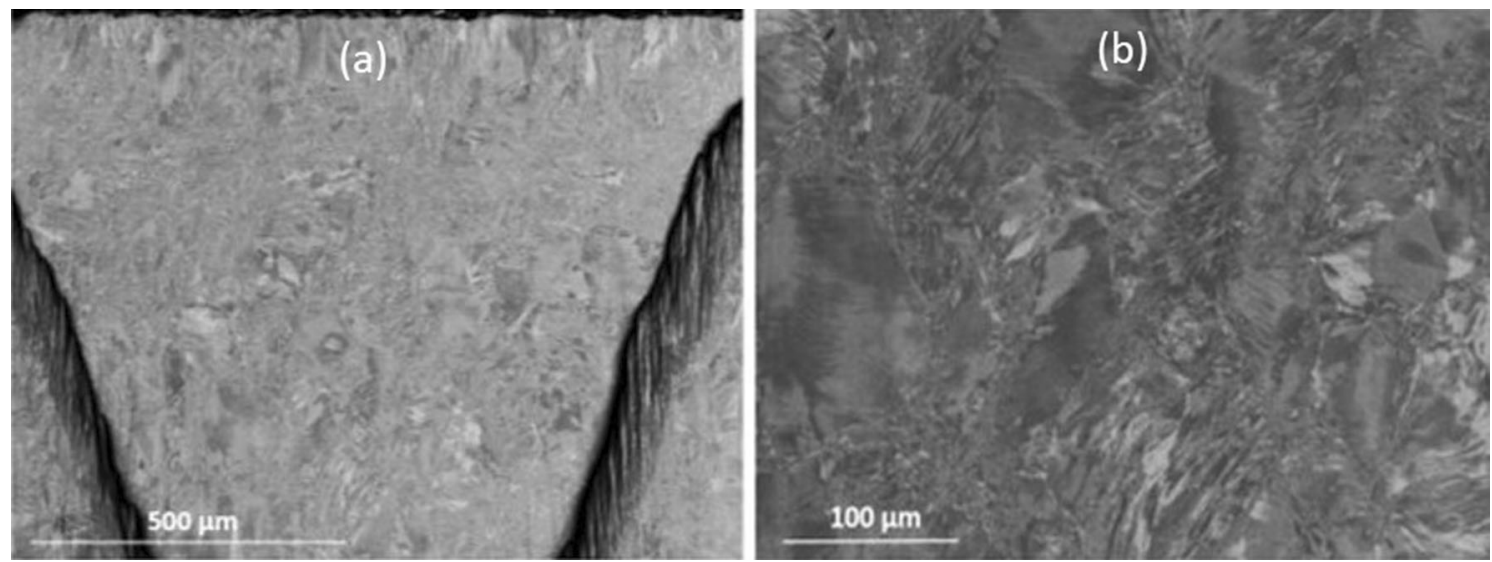

Fig. 5.- SEM images of Gum Metal after quasi-static compression at a strain rate of $0.001 \mathrm{~s}^{-1}$ taken at: $(a)$ low and (b) high magnification (loading direction is vertical in these images) obtained using a Hitachi SU8000. 

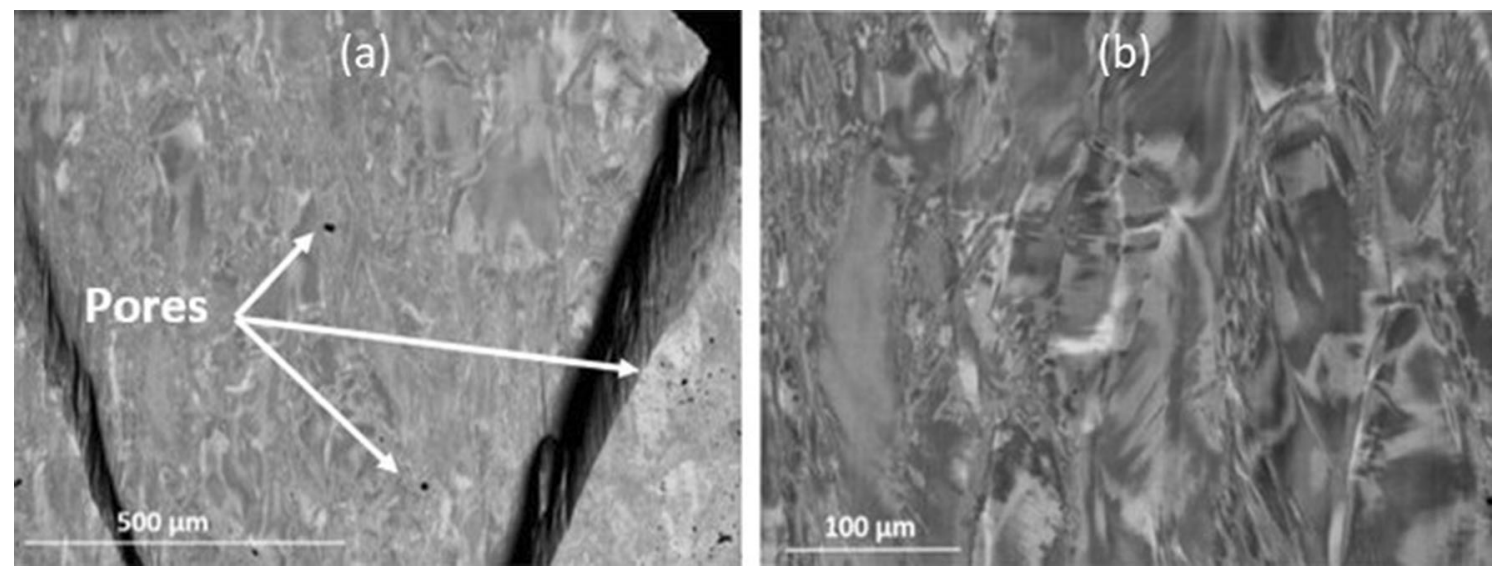

Fig. 6. - SEM images of Gum Metal after dynamic testing at a strain rate of $2100 \mathrm{~s}^{-1}$ taken at: (a) low and (b) high magnification (loading direction is vertical in these images) obtained using a Hitachi SU8000.

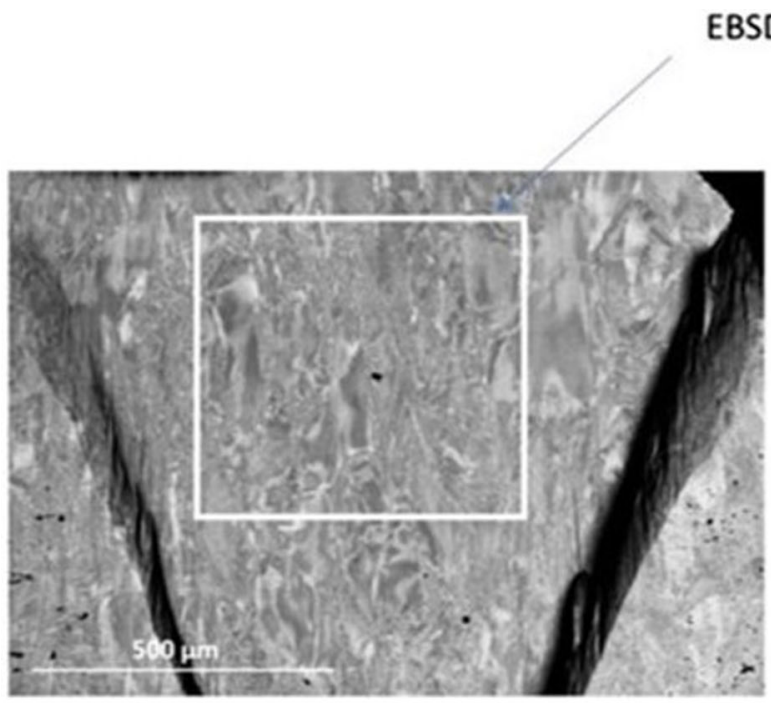

(a)

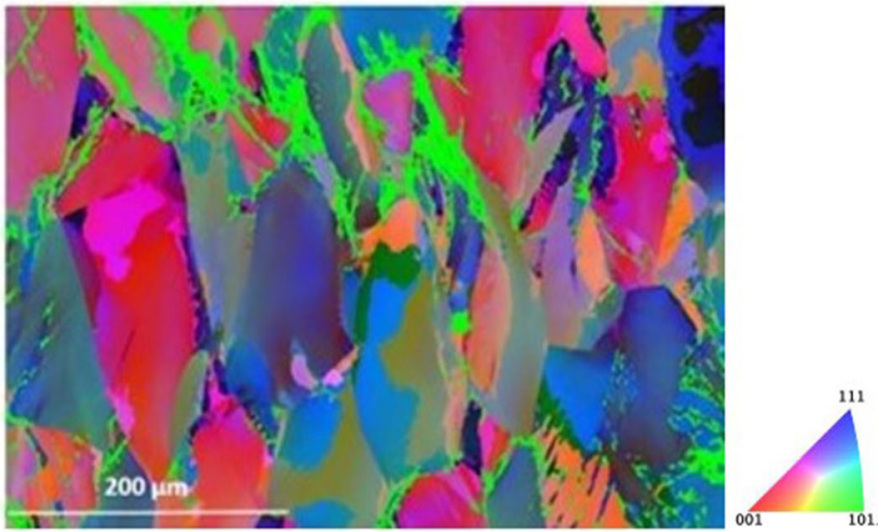

(b)

Fig. 7.- (a) SEM image of Gum Metal after dynamic compression at a strain rate of $2100 \mathrm{~s}^{-1}$ for a selected region and (b) its all-Euler angle EBSD crystallographic orientation map obtained using a Hitachi SU70.
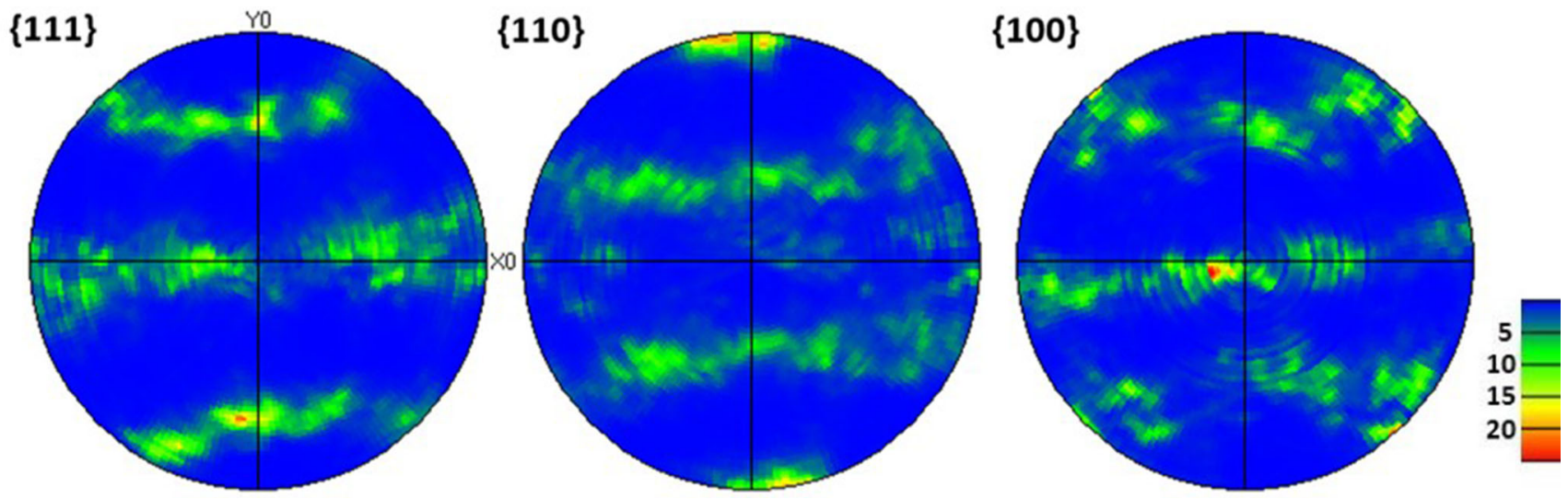

Fig. 8. - EBSD pole figures of Gum Metal after dynamic compression at a strain rate of $2100 \mathrm{~s}^{-1}$ obtained using a Hitachi SU70. 


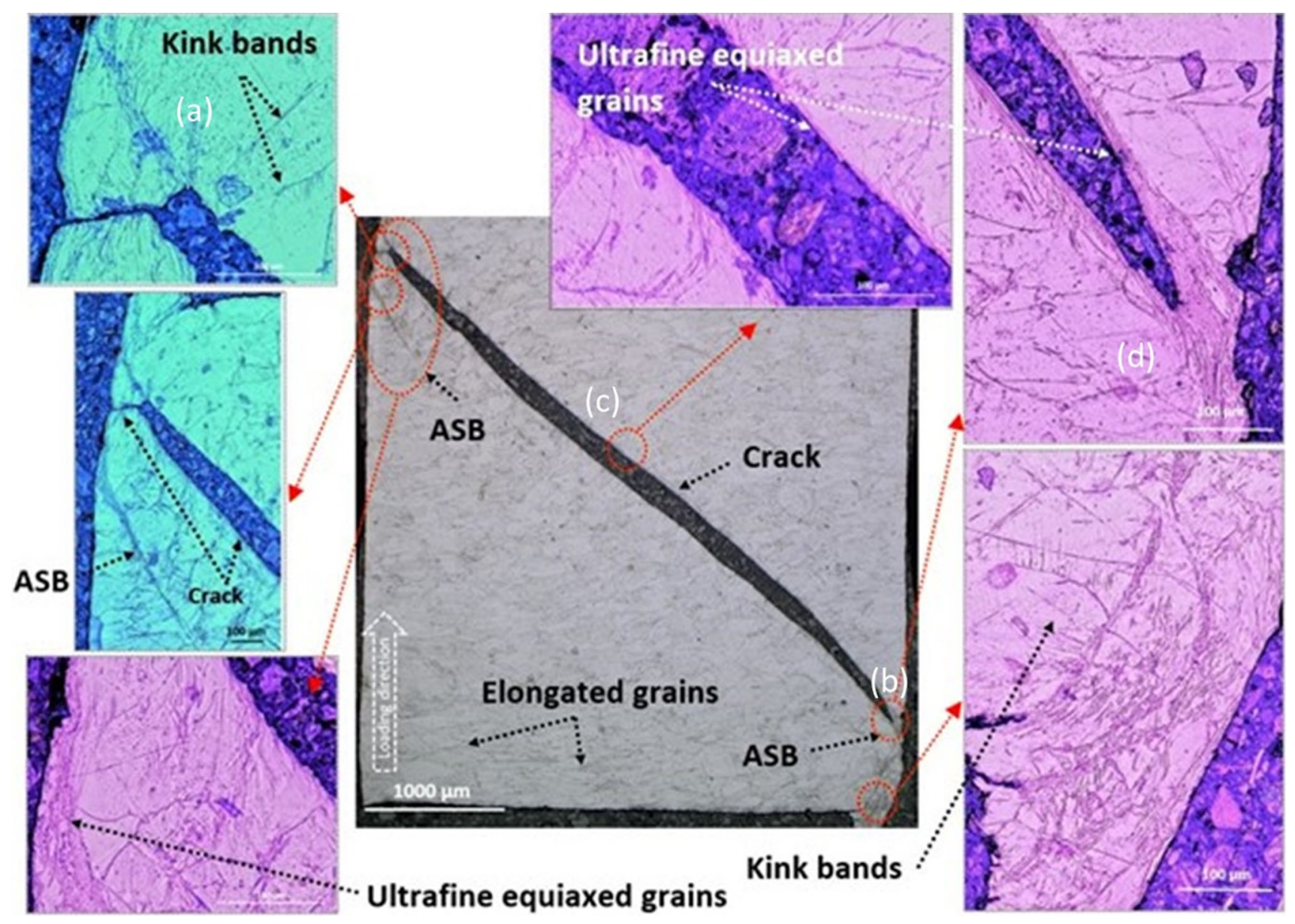

Fig. 9.- SEM images of Gum Metal after dynamic testing at a strain rate of $2270 \mathrm{~s}^{-1}$ with selected areas $(a)$ through $(d)$ obtained using a Phenom ProX.

can also be noticed that there is a temperature gradient athwart the ASB leading to a much more refined grain size in the middle of the ASB compared to the ASB/matrix boundaries ${ }^{[2]}$. The enlarged images in Figure 9 as well as the SEM images in Figure 10 reveal the typical deformation-induced surface composed of widely displaced deformation bands (kink bands), most of which are straight, although some curved ones are also observed. Most of the kink bands originate from the grain boundaries and propagate into the grain interiors. Twins are also observed after compression testing but in a very limited number; see Figure 10(c). In Figures 10(a) and (d) numerous deformed lamellae along with ultrafine recrystallized grains with the size of a few microns are present. It should be mentioned that these features occur throughout the ASBs and along the crack which occurred after the Hopkinson test. However, it is not possible to accurately evaluate the sizes of the recrystallized grains because of the highly deformed structure and because the resolution of the microscope used was too low. We believe that the recrystallized grains are $<5 \mu \mathrm{m}$ in diameter. Recrystallization in the ASBs may cause a reduction in the strength properties of the tested material. Figure 10(b) reveals both a recrystallized zone as well as, most likely, dislocation channels. As Figure 10(b) shows, the channels might traverse each other. Such interactions between channels with each other as well as with twin boundaries may lead to strain hardening. It is worth mentioning that the deformation mechanisms of $\beta$-Ti alloys vary depending on the stability of the alloys and can include dislocation slip, twinning and stress-induced martensitic transformation. ${ }^{[38-40]}$ The present study exhibits the occurrence of large deformations within the $\beta$ grains (see Fig. 10(c)). According to the literature, these large deformation bands are probably twins ${ }^{[38,41,42]}$ or kink bands ${ }^{[43,44]}$. It was proved that the formation of kink bands leads not only to enhancement of ductility and workability, but also to strain softening. ${ }^{[44,45]}$ Furthermore, ${ }^{[45]}$ indicates that with the increase in strain the misorientation within the grains also increases leading to crystal rotation in the grains causing strain softening, almost balancing the flow stress. Generally, the structure observed after dynamic loading is characterized by a crack and an adiabatic shear band formed at $\sim 45 \mathrm{deg}$ with respect to the loading direction as well as widely spaced deformation bands (kink bands).

Three types of deformation mechanisms regulating strain hardening and strain softening were found. Dislocations within the channels intersecting with twins may cause strain hardening while recrystallized grains and kink bands with crystal rotation inside the grains may lead to strain softening. 

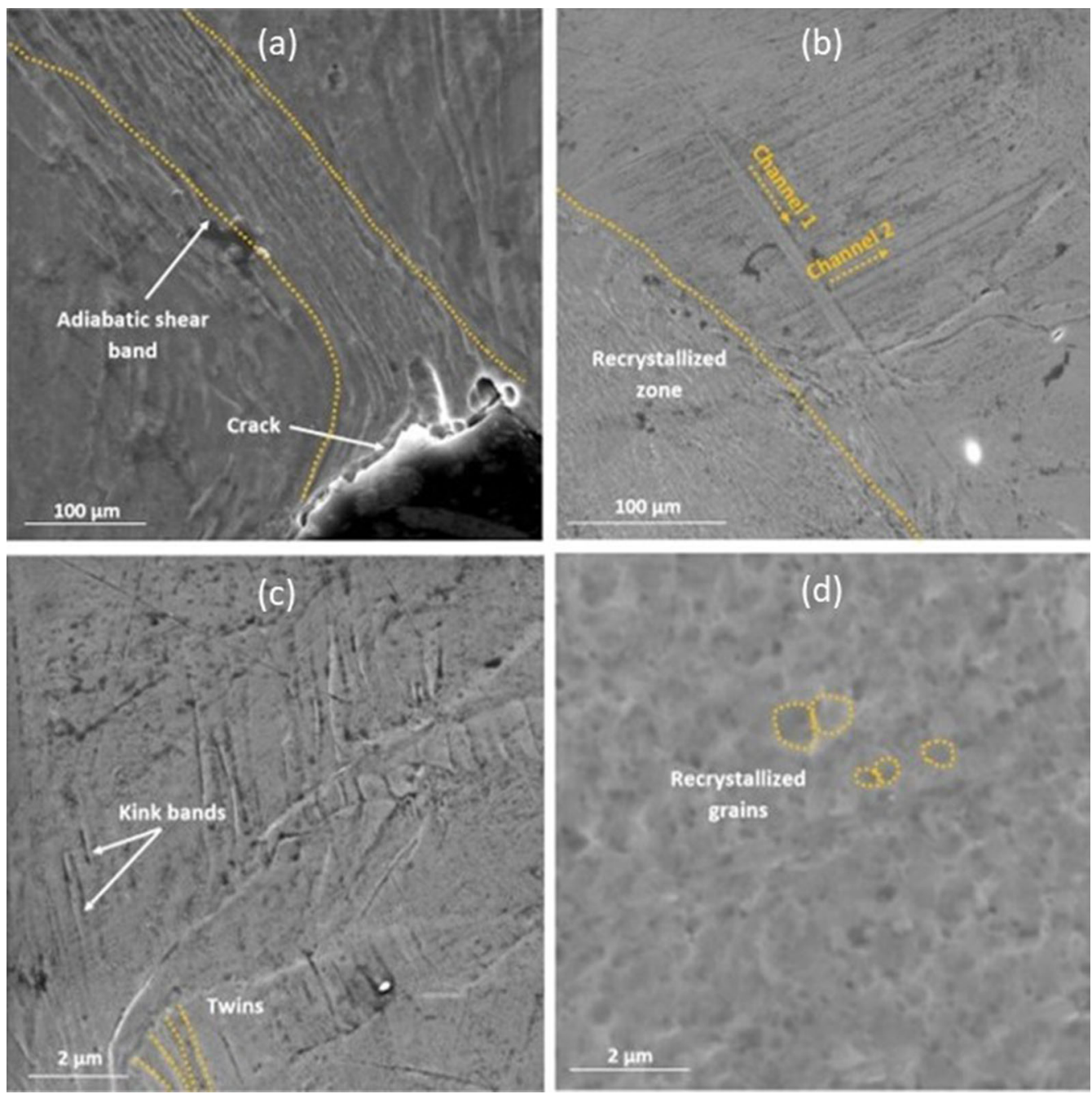

Fig. 10.- SEM images of Gum Metal after dynamic testing at a strain rate of $2270 \mathrm{~s}^{-1}$ taken for the selected areas $(a)$ through $(d)$ chosen in Fig. 9 obtained using a Phenom ProX.

EBSD was also used to characterize the deformation products in Gum Metal after a Hopkinson test at a strain rate of $2270 \mathrm{~s}^{-1}$; see Figure 11. The observations were realized on a cross section that was parallel to the direction of compression and about 1 to $2 \mathrm{~mm}$ from the fracture inside the specimen. Crystallographic misorientation (CMO) between the $\beta$ matrix and formed deformations were observed. It should be noted that to simplify the analysis it has been assumed that all formed crystal structures were body-centered cubic as they were unknown until now. Figure 11(a) clearly shows that the colors of the thick laths as well as thin lines differ from the $\beta$ matrix. This is the evidence of differences in both the crystal structures and crystallographic orientations. Even though the directions and sizes of the thick laths ( $\sim 5$ to $10 \mu \mathrm{m})$ were irregular, the crystallographic misorientation between them and the matrix is quite uniform and is around $50 \mathrm{deg}$ (Figure 11(b)). It is known that around $\langle 110\rangle \beta$ the crystallographic misorientation of the matrix with $\{332\}\langle 113\rangle \beta$ twins and $\{112\}\langle 111\rangle \beta$ twins is 50.5 and $70.3 \mathrm{deg}$, respectively ${ }^{[34,46-52]}$. Therefore, it can be concluded that the thick laths in the dynamically deformed alloy are $\{332\}\langle 113\rangle \beta$. A slight deviation from the $\mathrm{CMO}$ angle of $50.5 \mathrm{deg}$ (decrease of $\mathrm{CMO}$ up to $\sim 38 \mathrm{deg}$; see Figure 11(c)) reveals that the crystal rotation took place in more distorted $\{332\}\langle 113\rangle \beta$ twins. Figure 11(d) shows that structures with a CMO $<30$ deg were also detected. Quite similar structures in a Ti-23Nb-0.7Ta-2Zr- $1.2 \mathrm{O}$ alloy with 40 pet cold swaging and in cold-compressed Ti-44.4Nb-0.73Ta-2Zr-1.34O were observed in. ${ }^{[16,34]} \mathrm{In},{ }^{[16]}$ it is claimed that such a type of deformed structures may be induced by dislocation-free deformation. Nevertheless, the authors believe that these are the kick bands.

Finally, in Figures 12(b) through (d) an inverse pole figure (IPF), an all-Euler and band contrast maps from EBSD are shown, respectively. From these maps, a striking observation can be made regarding the microstructure within the ASB, which formed in the sample after dynamic testing at a strain rate of $2270 \mathrm{~s}^{-1}$. Remarkable grain refinement took place within the ASB suggesting a significant temperature rise during dynamic loading. The observed ultrafine equiaxed microstructure 

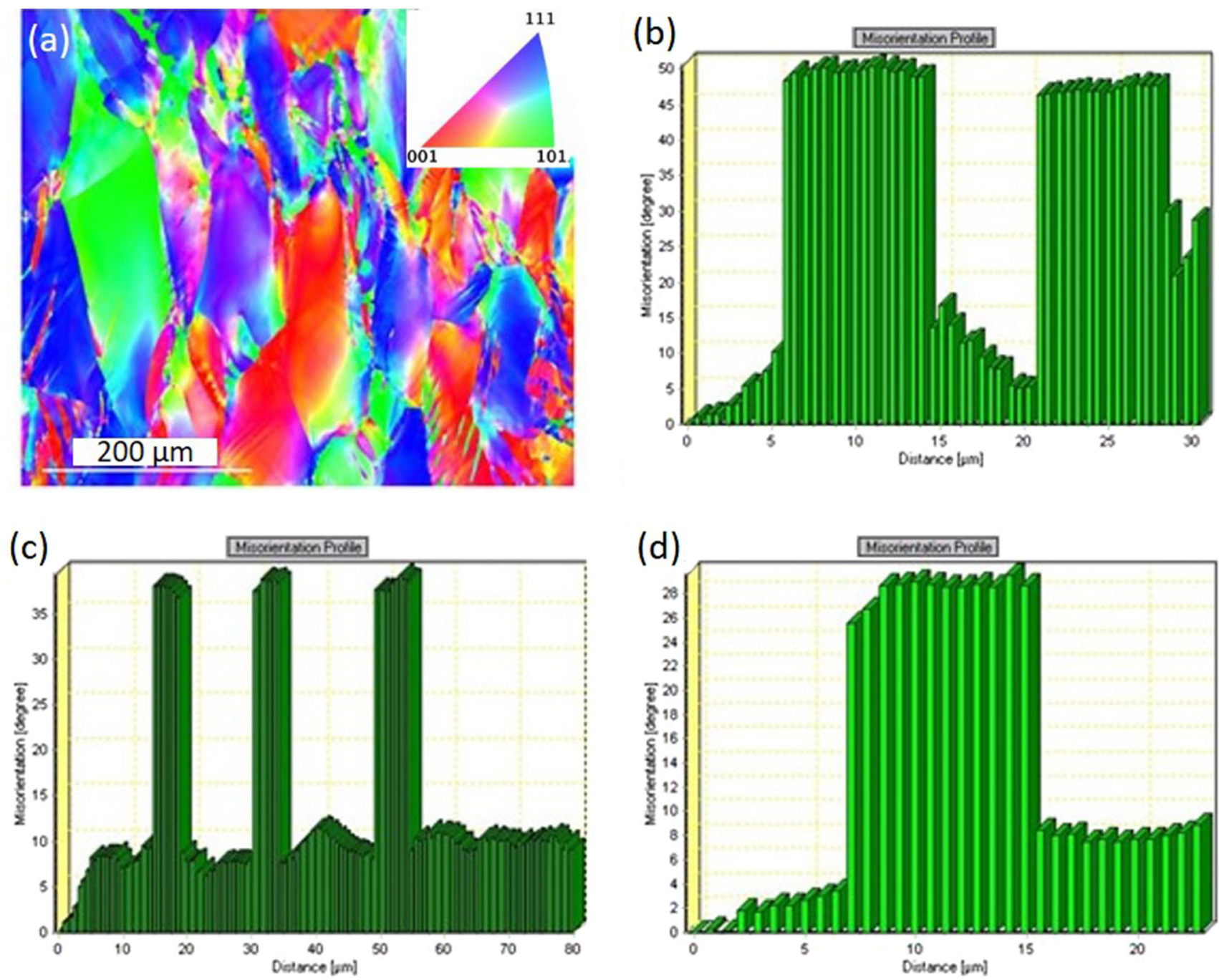

Fig. 11.-(a) Inverse pole figure map of Gum Metal after dynamic compression at a strain rate of $2270 \mathrm{~s}^{-1}$ obtained $1 \mathrm{~mm}$ below the observed crack and $(b)$ through $(d)$ misorientation profiles obtained using a Hitachi SU70.

is composed of grains of size significantly below $1 \mu \mathrm{m}$. Similar findings were published ${ }^{\left[{ }^{[30]}\right.}$ where the canonical ASB pattern was revealed together with the shear flow of the grains within the ASB near the ASB/matrix boundaries.

Phase compositions were detected for four samples: (1) Gum Metal in its initial state; (2) after quasi-static testing with a strain rate of $10^{0} \mathrm{~s}^{-1}$; (3) after dynamic testing with a strain rate of $870 \mathrm{~s}^{-1}$; (4) after dynamic testing with a strain rate of $1100 \mathrm{~s}^{-1}$; see Figure 13 . Additionally, Figure 13 shows enlargements of selected parts of the graphs. The XRD profiles exhibit that all the samples are composed mostly of $\beta$ (bcc) phases with the preferred orientation of (110). In the enlarged parts of the graphs in Figure 13, the appearance of stress-induced martensite $\alpha^{\prime \prime}$ (SIM $\alpha^{\prime \prime}$ ) has been detected. This observation is consistent with the literature results about both $\beta$-titanium alloys and Gum Metals with similar chemical compositions where deformation induces martensitic transformation. ${ }^{[51-57]}$ It was noticed that with the increase in the strain rate, the intensities of the $\beta$ (200) peaks slightly decrease. The result implies that the $\beta$ (200) phase is consumed by the $\beta \rightarrow \alpha^{\prime \prime}$ transformation during static and dynamic compression ${ }^{[44]}$.

The $\omega$ phase is not easily detected by using XRD. The weak peaks from the stress-induced $\omega$ phase arise for the sample after dynamic testing with a strain rate of $1100 \mathrm{~s}^{-1}$ but they are very difficult to identify from the background. However, the presence of the $\omega$ phase in Gum Metal has been confirmed in many studies. ${ }^{[46-57]}$

\section{CONSTITUTIVE MODEL OF GUM METAL UNDER COMPRESSION}

Constitutive models are essential in any theoretical modeling to predict material behavior under various loading conditions. ${ }^{[58]}$ The Johnson-Cook $(\mathrm{J}-\mathrm{C})$ model is widely used in numerical consideration of material structures subjected to dynamic loadings because of its simple structure and the small number of material parameters. ${ }^{[58,59]}$ It is expressed by Eq. [2].

$$
\sigma=\left(A+B \varepsilon^{n}\right)\left(1+C \ln \left(\dot{\varepsilon}^{*}\right)\right)\left(1-T^{* m}\right)
$$



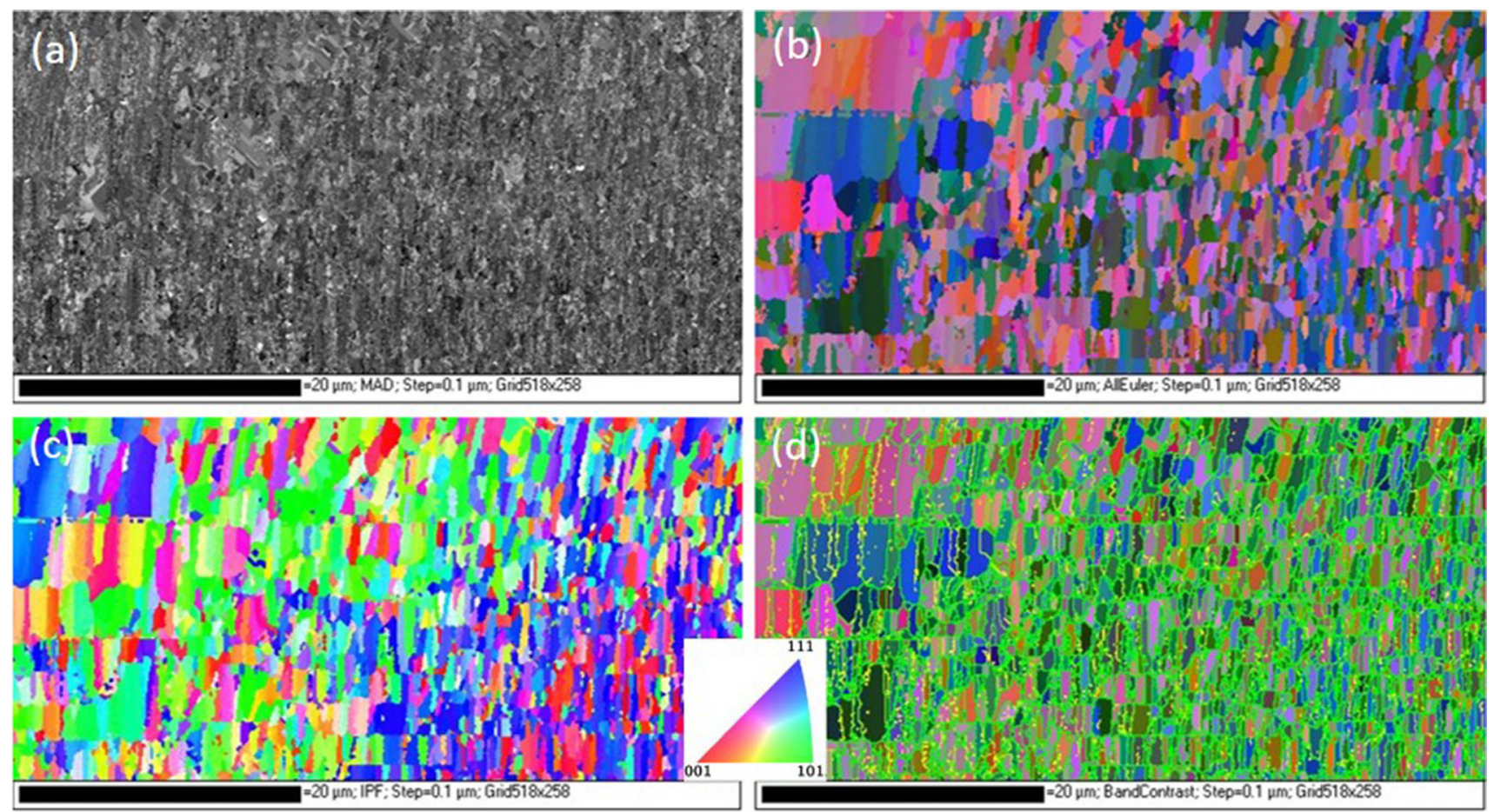

Fig. 12.-(a) SEM image of an ASB formed in Gum Metal after dynamic compression at a strain rate of $2270 \mathrm{~s}^{-1}$ and $(b)$ its inverse pole figure, (c) an all-Euler, $(d)$ band contrast maps from EBSD obtained using a Hitachi SU70.

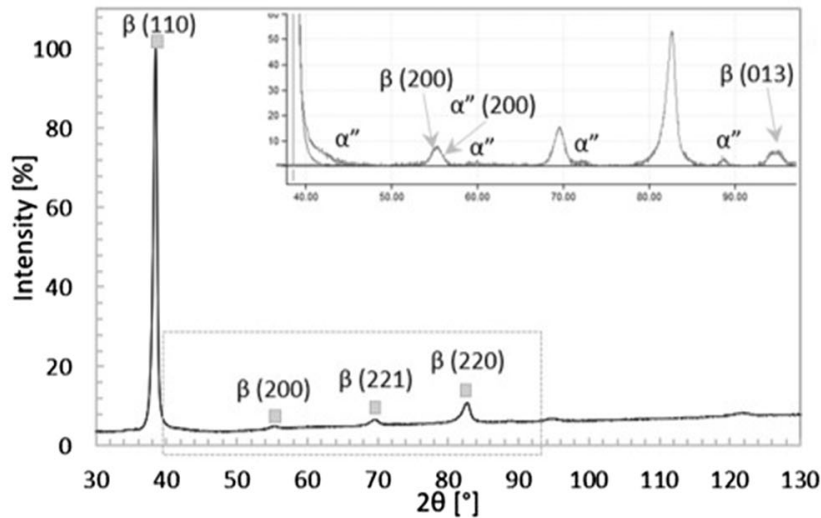

(a)

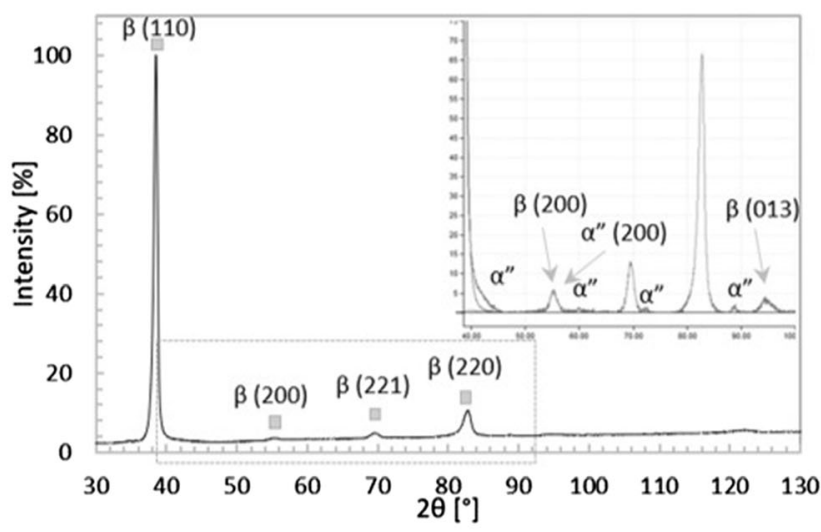

(c)

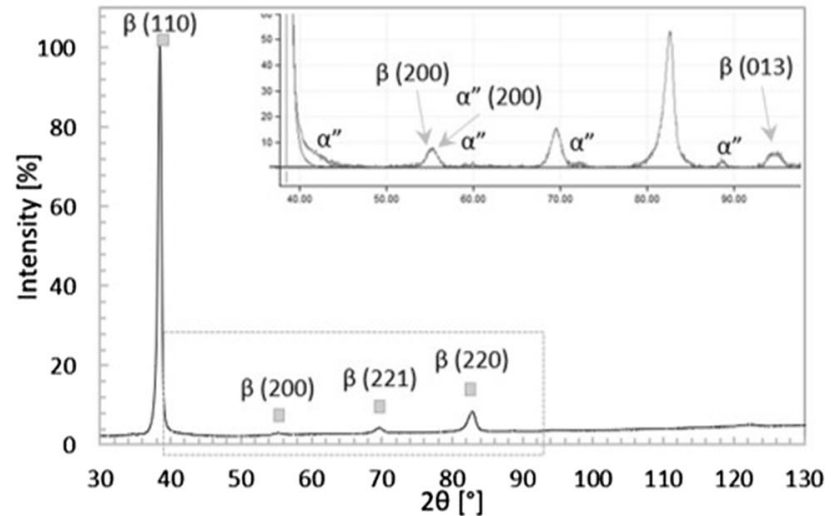

(b)

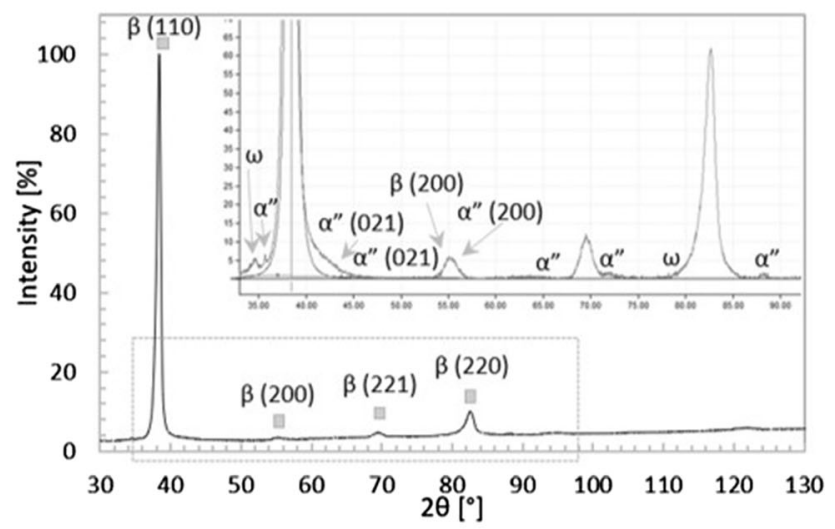

(d)

Fig. 13. - XRD profiles of (a) Gum Metal in its initial state; $(b)$ after quasi-static testing with a strain rate of $10^{0} \mathrm{~s}^{-1} ;(c)$ after dynamic testing with a strain rate of $870 \mathrm{~s}^{-1} ;(d)$ after dynamic testing with a strain rate of $1100 \mathrm{~s}^{-1}$. 
where $\varepsilon$ is the equivalent plastic strain; $\dot{\varepsilon}^{*}=\dot{\varepsilon} / \dot{\varepsilon}_{0}$ is the dimensionless plastic strain rate for $\dot{\varepsilon}_{0}=1 \mathrm{~s}^{-1} ; T^{*}$ is the homologous temperature; $A, B, n, C$ and $m$ are the material constants.

However, the $\mathrm{J}-\mathrm{C}$ model has many limitations, of which the most problematic is the description of work-hardening behavior. This problem has already been pointed out in, ${ }^{[60]}$ in which the authors state that the $\mathrm{J}-\mathrm{C}$ model is not appropriate for materials exhibiting large changes in hardening behavior at different strain rates. Moreover, according to ${ }^{[61]}$ in which constitutive modeling for the Ti6554 alloy was considered, the $\mathrm{J}-\mathrm{C}$ model is inadequate for describing complex strain-hardening behavior, especially that characterized by a negative work-hardening ratio. Therefore, it was decided to use a modified form of the $\mathrm{J}-\mathrm{C}$ model, which was proposed in, ${ }^{[62]}$ to improve the parameterization of constitutive modeling for an A356 aluminum alloy that exhibits the strain-softening mechanism. The model is defined by Eq. [3]

$$
\sigma=\left(A_{\mathrm{ss}} \varepsilon^{B_{\mathrm{ss}}+C_{\mathrm{ss}} \varepsilon+D / \varepsilon}\right)\left(1+E \ln \left(\dot{\varepsilon}^{*}\right)\right) \exp \left(F T^{*}\right)
$$

where $A_{\mathrm{ss}} \varepsilon^{B_{\mathrm{ss}}+C_{\mathrm{ss}} \varepsilon+D / \varepsilon}$ term describes the strain-softening mechanism; $A_{\mathrm{ss}}, B_{\mathrm{ss}}, C_{\mathrm{ss}}$ and $D$ are the material constants; $E$ is a coefficient determining strain rate sensitivity; $F$ is the parameter reflecting the thermal softening mechanism (the subscript ss, meaning "strain softening," was introduced to differentiate the constant symbols used in the abovementioned $\mathrm{J}-\mathrm{C}$ models).

In the present work, the experimental study of the mechanical behavior of the Gum Metal alloy was performed at room temperature. Therefore, a simplified

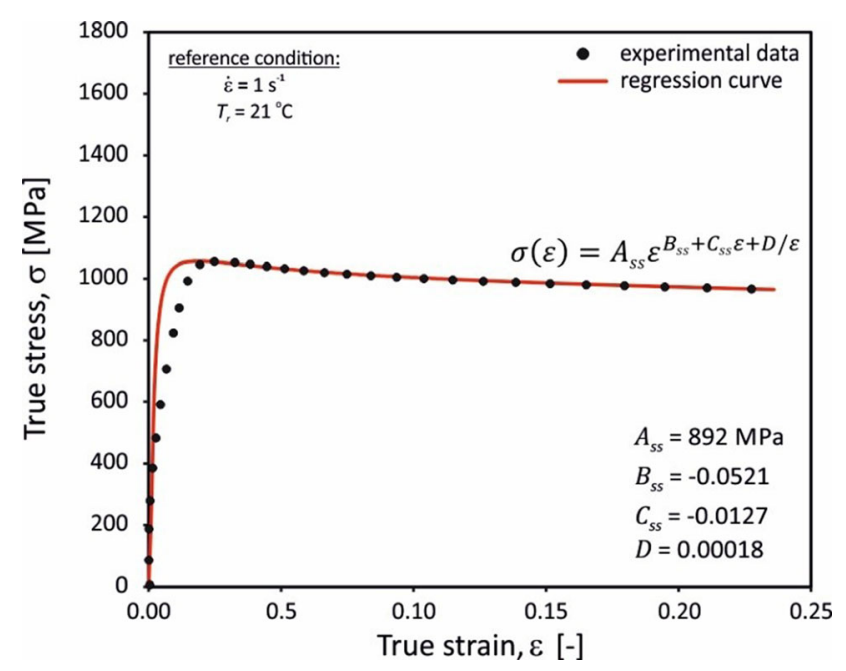

Fig. 14.-Fitting the model curve of $\sigma(\varepsilon)$ to experimental data of Gum Metal under compression at the strain rate of $1 \mathrm{~s}^{-1}$. form of the constitutive Eq. [3], without any thermal component, was used.

The constants $A_{\mathrm{ss}}, B_{\mathrm{ss}}, C_{\mathrm{ss}}$ and $D$ were determined using regression analysis assuming reference conditions $\left(\dot{\varepsilon}_{0}=1 \mathrm{~s}^{-1}\right.$, reference temperature $T_{r}=21{ }^{\circ} \mathrm{C}$ ). Fitting the $\mathrm{J}-\mathrm{C}$ model curve to the experimental data and the constitutive relationship with the values of the material constants is presented in Figure 14. It can be concluded that $>95$ pct of the data points are very close to the regression curve, which evidences excellent parameterization of the applied model. However, it should be emphasized here that material constant values are very sensitive to the initial (input) values declared during regression analysis. The impact of the initial value of the constant $A_{\mathrm{ss}}$ is especially strong. In this model, the initial value of constant $A_{\mathrm{ss}}$ equal to the value of yield stress (1026 MPa) determined under the reference experiment condition was assumed.

The procedure of determination of $E$ is more complex. As Figure 3 shows, strain rate hardening of Gum Metal is not linear and depends on the strain. Thus, the value of $E$ is not constant. The application of a classical approach to determine it from the slope of the fitting line of the plot $\frac{\sigma}{A_{\mathrm{ss}} \varepsilon_{B_{\mathrm{ss}}+C_{\mathrm{ss}} \varepsilon+D / \varepsilon}}-1 \mathrm{vs} \cdot \ln \left(\dot{\varepsilon}^{*}\right)$ is not appropriate. Therefore, to achieve a high estimation accuracy of the constitutive model, the parameter $E$ is defined as a second-degree polynomial with two variables $\varepsilon$ and $\dot{\varepsilon}$. Thus, the function of $E$ represents the surface, which can be expressed by Eq. [4].

$$
E(\varepsilon, \dot{\varepsilon})=E_{1}+E_{2} \varepsilon+E_{3} \dot{\varepsilon}+E_{4} \dot{\varepsilon} \dot{\varepsilon}+E_{5} \varepsilon^{2}+E_{6} \dot{\varepsilon}^{2}
$$

The values of regression coefficients $E_{1}-E_{6}$ were collected in Table I; in turn, a regression surface $E(\varepsilon, \dot{\varepsilon})$ is shown in Figure 15.

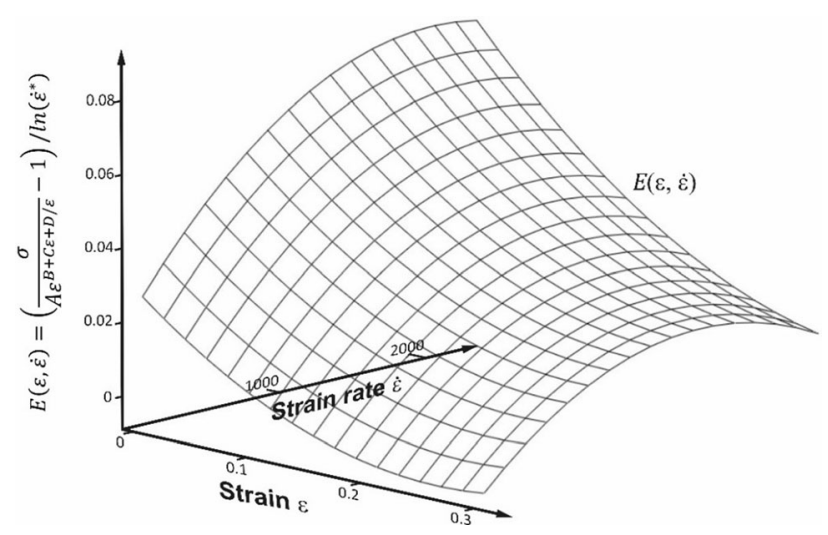

Fig. 15.- Regression surface of parameter $E(\varepsilon, \dot{\varepsilon})$ of the tested Gum Metal.

Table I. Regression Coefficients $E_{1}-E_{6}$

\begin{tabular}{lccccc}
\hline$E_{1}$ & $E_{2}$ & $E_{3}$ & $E_{4}$ & $E_{5}$ & $E_{6}$ \\
\hline 0.027 & -0.257 & $5.556 \times 10^{-5}$ & $-4.624 \times 10^{-5}$ & 0.496 & $-1.41 \times 10^{-8}$ \\
\hline
\end{tabular}




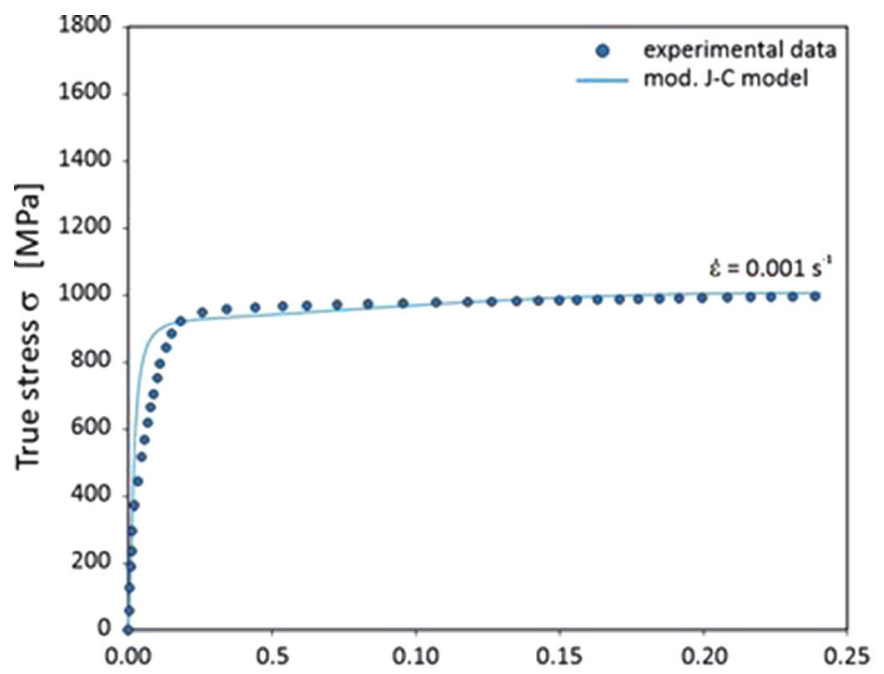

(a)

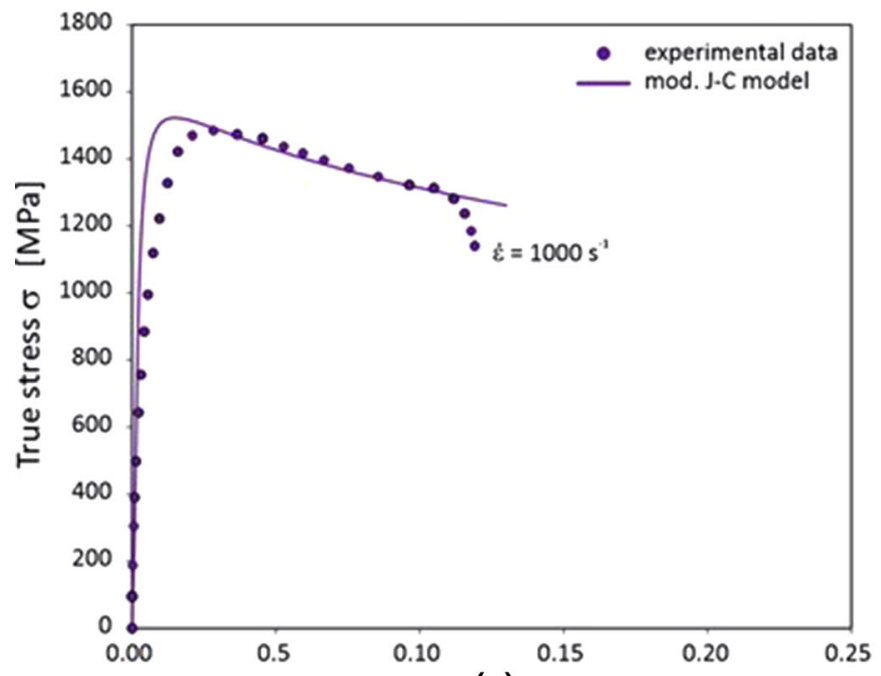

(c)

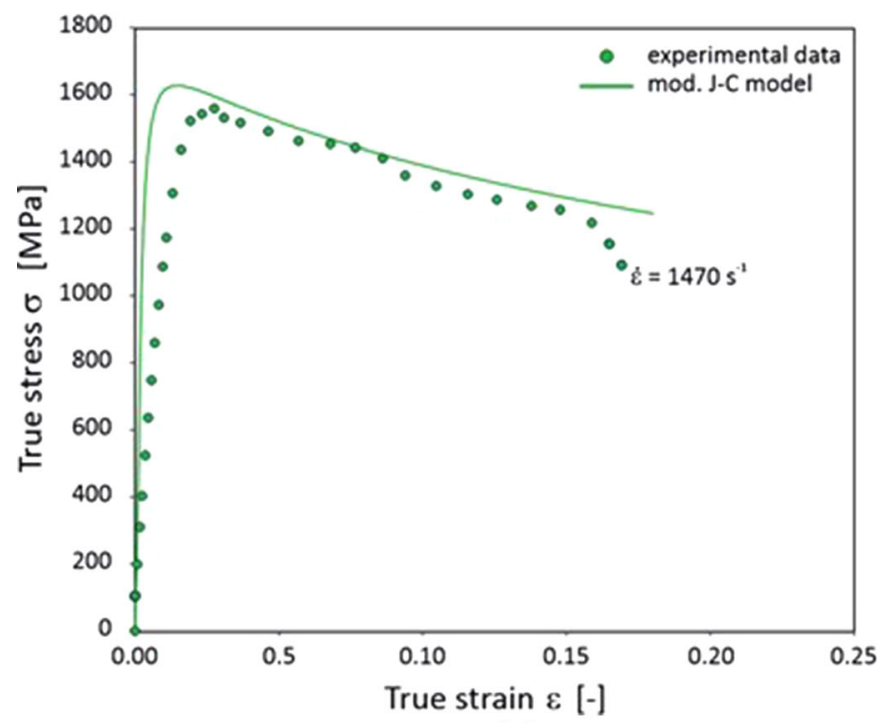

(e)

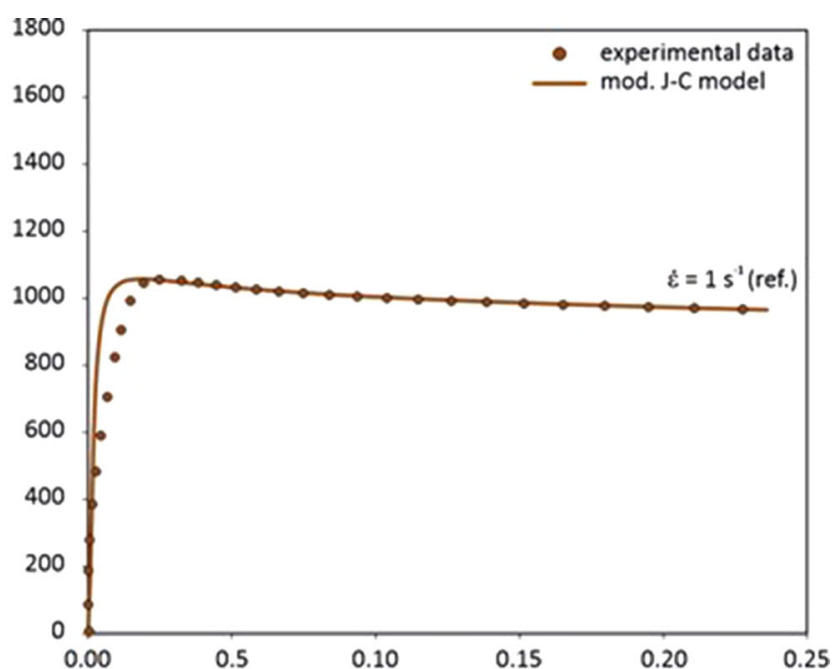

(b)

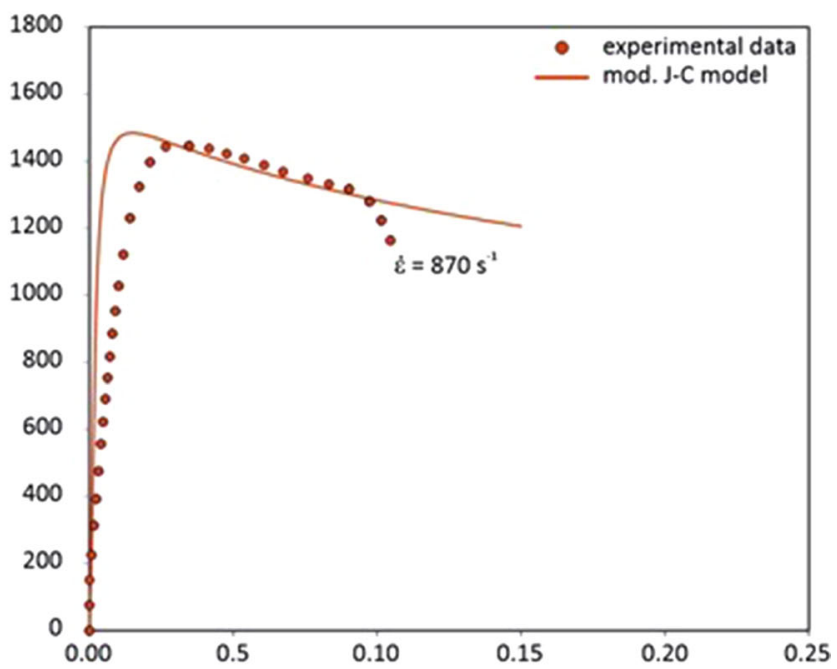

(d)

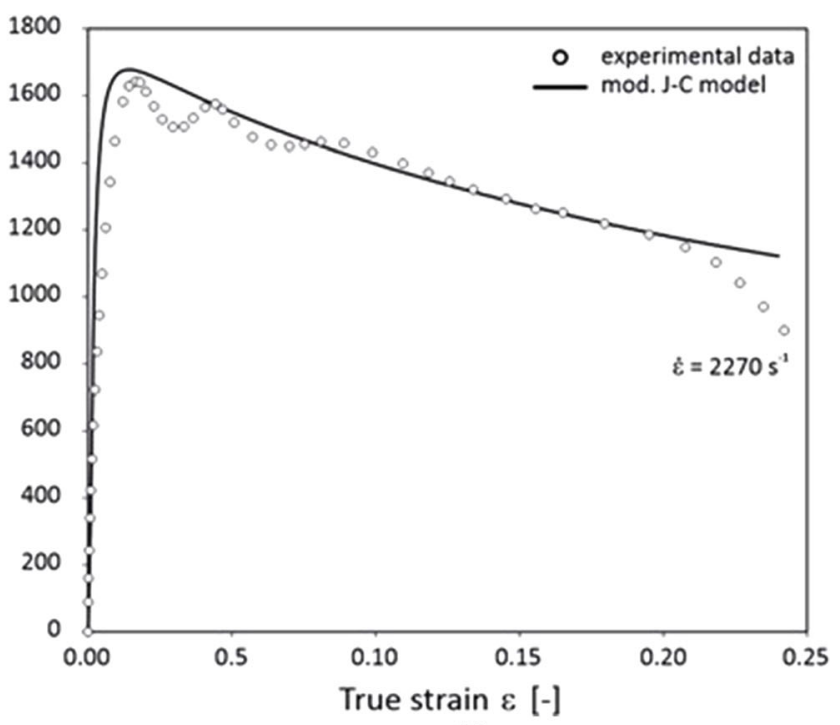

(f)

Fig. 16. - Comparison of the experimental data and the modified J-C model for the tested Gum Metal under quasi-static compression at strain rates of $(a) 0.001 \mathrm{~s}^{-1} ;(b) 1 \mathrm{~s}^{-1}$ and dynamic compression at strain rates of $(c) 870 \mathrm{~s}^{-1} ;(d) 1000 \mathrm{~s}^{-1} ;(e) 1470 \mathrm{~s}^{-1} ;(f) 2270 \mathrm{~s}^{-1}$. 
To verify the modified J-C constitutive model formulated using the identified material parameters, it was compared with the experimental data for all monotonic and high strain rates and plotted in Figures 16(a) through (f). In general, a very good agreement between the experimentally obtained data and the model can be seen. The strain-softening behavior (decreasing of the flow stress with increasing strain) of Gum Metal is correctly described using the modified $\mathrm{J}-\mathrm{C}$ model with the term $A_{\mathrm{ss}} \varepsilon^{B_{\mathrm{ss}}+C_{\mathrm{ss}} \varepsilon+D / \varepsilon}$. Moreover, the polynomial form of the parameter $E$, which determines the strain rate sensitivity with the interaction between strain and strain rate, improves the accuracy of the modified $\mathbf{J}-\mathrm{C}$ model for a wide range of strains and strain rates.

\section{CONCLUSION}

In this work, the original Gum Metal fabricated by Toyota Central Research and Development Laboratories was subjected to mechanical characterization under quasi-static and dynamic compression using an electromechanical testing machine and a SHPB technique, respectively. The microstructural features of the Gum Metal samples after loading were evaluated using optical microscopy, SEM and EBSD. Based on the experimental results, the mechanical responses of Gum Metal were modeled.

The following conclusions can be drawn:

1. The mechanical behavior of Gum Metal presented in the stress-strain curves obtained for the alloy tested under monotonic and dynamic loadings revealed a strain-softening effect which intensified with increasing strain rate. Moreover, the plastic flow stress was observed to increase both for static and dynamic loading conditions with increasing strain rate. In turn, the strain rate sensitivity $m$ was seen to decrease with increasing strain rate.

2. Microstructural deformation mechanisms regulating strain hardening and strain softening were identified. A crack and an adiabatic shear band formed at $\sim 45 \mathrm{deg}$ with respect to the loading direction, and widely spaced deformation bands (kink bands) were observed. Dislocations within the channels intersecting with twins may cause strain hardening while recrystallized grains and kink bands with crystal rotation inside the grains may lead to strain softening.

3. Good agreement between the experimental and numerical data obtained using the modified Johnson-Cook model was achieved.

\section{ACKNOWLEDGMENTS}

Support of the National Science Center $(\mathrm{NCN})$ in Poland through grant Nos. 2016/23/N/ST8/03688 and 2017/27/B/ST8/03074 is acknowledged. The authors are grateful to Prof. Naohisa Takesue from Fukuoka
University, Prof. Shigeru Kuramoto from Ibaraki University and Dr. Tadahiko Furuta from the Toyota Central Research and Development Laboratories for long-term scientific collaboration and providing the Gum Metal alloy. The authors also thank Leszek Urbański from IPPT PAN for machining Gum Metal specimens and discussions regarding the experimental procedures.

\section{OPEN ACCESS}

This article is licensed under a Creative Commons Attribution 4.0 International License, which permits use, sharing, adaptation, distribution and reproduction in any medium or format, as long as you give appropriate credit to the original author(s) and the source, provide a link to the Creative Commons licence, and indicate if changes were made. The images or other third party material in this article are included in the article's Creative Commons licence, unless indicated otherwise in a credit line to the material. If material is not included in the article's Creative Commons licence and your intended use is not permitted by statutory regulation or exceeds the permitted use, you will need to obtain permission directly from the copyright holder. To view a copy of this licence, visit http://creat ivecommons.org/licenses/by $/ 4.0 /$.

\section{REFERENCES}

1. T. Saito, T. Furuta, J.H. Hwang, S. Kuramoto, K. Nishino, N. Suzuki, R. Chen, A. Yamada, K. Ito, Y. Seno, T. Nonaka, H. Ikehata, N. Nagasako, C. Iwamoto, Y. Ikuhara, and T. Sakuma: Science, 2003, vol. 300, pp. 464-67.

2. S. Kuramoto, T. Furuta, J. Hwang, K. Nishino, and T. Saito: Mater. Sci. Eng. A, 2006, vol. 442, pp. 454-57.

3. S. Kuramoto, T. Furuta, J.H. Hwang, K. Nishino, and T. Saito: Metall. and Mat. Trans. A, 2006, vol. 37, pp. 657-62.

4. M. Niinomi, M. Nakai, and J. Hieda: Acta Biomater., 2012, vol. 8, pp. 3888-3903.

5. D.M. Gordin, R. Ion, C. Vasilescu, S.I. Drob, A. Cimpean, and T. Gloriant: Mater. Sci. Eng. C, 2014, vol. 44, pp. 362-70.

6. K.M. Golasiński, R. Detsch, M. Szklarska, B. Łosiewicz, M. Zubko, S. Mackiewicz, E.A. Pieczyska, and A.R. Boccaccini: J. Mech. Behav. Biomed., 2021, vol. 115, pp. 104289-4311.

7. D.P. Perl and A.R. Brody: Science, 1980, vol. 208, p. 208.

8. J. Domingo: Biol. Trace. Elem. Res., 2002, vol. 88, pp. 97-112.

9. M. Tahara, H.Y. Kim, T. Inamura, H. Hosoda, and S. Miyazaki: Acta Mater., 2011, vol. 59, pp. 6208-18.

10. L.S. Wei, H.Y. Kim, T. Koyano, and S. Miyazaki: Scripta Mater., 2016, vol. 123, pp. 55-58.

11. H.Y. Kim, L. Wei, S. Kobayashi, M. Tahara, and S. Miyazaki: Acta Mater., 2013, vol. 61, pp. 4874-86.

12. E.A. Pieczyska and M. Maj:T. Furuta and S. Kuramoto S in Advances in Mechanics: Theoretical, Computational and Interdisciplinary Issues, M. Kleiber, ed., CRC Press/Balkema Taylor\&Francis Group, London, 2016, pp. 469-72.

13. K.M. Golasiński, E.A. Pieczyska, M. Staszczak, M. Maj, T. Furuta, and S. Kuramoto: Quant. InfraRed Thermogr. J., 2017, vol. 14, pp. 226-33.

14. E.A. Pieczyska, M. Maj, K. Golasiński, M. Staszczak, T. Furuta, and S. Kuramoto: Materials, 2018, vol. 11, p. 567.

15. H. Ikehata, N. Nagasako, S. Kuramoto, and T. Saito: MRS Bull., 2006, vol. 31, pp. 688-92

16. T. Furuta, S. Kuramoto, J.W. Morris, N. Nagasako, E. Withey, and D.C. Chrzan: Scripta Mater., 2013, vol. 68, pp. 767-72. 
17. T. Yano, Y. Murakami, D. Shindo, and S. Kuramoto: Acta Mater., 2009, vol. 57, pp. 628-33.

18. J. Coakley, V.A. Vorontsov, K.C. Littrell, R.K. Heenan, M. Ohnuma, N.G. Jones, and D. Dye: J. Alloys. Comp., 2015, vol. 623 , pp. 146-56.

19. T. Yano, Y. Murakami, D. Shindo, Y. Hayasaka, and S. Kuramoto: Scripta Mater., 2010, vol. 63, pp. 536-39.

20. M. Tane, T. Nakano, S. Kuramoto, M. Niinomi, N. Takesue, and H. Nakajima: Acta Mater., 2013, vol. 61, pp. 139-50.

21. E. Plancher, C.C. Tasan, S. Sandloebes, and D. Raabe: Scripta Mater., 2013, vol. 68, pp. 805-08.

22. M.J. Lai, C.C. Tasan, and D. Raabe: Acta Mater., 2015, vol. 100, pp. 290-300.

23. M.J. Lai, C.C. Tasan, and D. Raabe: Acta Mater., 2016, vol. 11, pp. $173-86$

24. K. Golasiński, E. Pieczyska, M. Maj, M. Staszczak, P. Świec, T. Furuta, and S. Kuramoto: Archiv. Civ Mech. Eng., 2020, vol. 20 , pp. 1-14.

25. K. Kowalczyk-Gajewska, E.A/ Pieczyska, K. Golasiński, M. Maj, S. Kuramoto, and T. Furuta: Int. J. Plast., 2019, vol. 119, pp. 85-101.

26. K. Golasiński, E. Pieczyska, M. Maj, S. Mackiewicz, M. Staszczak, Z. Kowalewski, L. Urbański, M. Zubko, and N Takesue: Mater. Sci., 2020, vol. 36, pp. 996-1002.

27. D.R. Chichili, K.T. Ramesh, and K.J. Hemker: Acta Mater., 1998, vol. 46, pp. 1025-43.

28. Y. Long, W. Zhang, L. Peng, H. Peng, X. Li, and X. Huang: Metall. Mater. Trans. A, 2020, vol. 51, pp. 4765-76.

29. H. Zhan, W. Zeng, G. Wang, D. Kent, and M. Dargusch: Mater. Charact., 2015, vol. 102, pp. 103-113.

30. S. Liu, Z..L. Pan, Y.H. Zhao, T. Topping, R.Z. Valiev, X.Z. Liao, E.J. Lavernia, Y.T. Zhug, and Q. Wei: Acta Mater., 2017, vol. 132, pp. 193-208.

31. H. Kolsky: Appl. Mech. Rev., 1958, vol. 11, pp. 465-68.

32. W.W. Chen and B. Song: Split Hopkinson (Kolsky) Bar: Design, Testing and Applications, 1st ed., Springer, New York, 2011.

33. W. Guo, M.Z. Quadir, S. Moricca, T. Eddows, and M. Ferry: Mater. Sci. Eng. A, 2013, vol. 575, pp. 206-16.

34. Y. Yang, S.Q Wu, G.P. Li, Y.L. Li, Y.F. Lu, K. Yang, and P. Ge: Acta Mater., 2010, vol. 58, pp. 2778-87.

35. H. Xing, J. Sun, Q. Yao, W.Y. Guo, and R. Chen: Appl. Phys. Lett., 2008, vol. 92, p. 151905.

36. M. Schwartz: New Materials, Processes, and Methods Technology, 1st ed., CRC Press, Boca Raton, 2005.

37. Y. Yiang, G.P. Li, G.M. Cheng, Y.L. Li, and K. Yiang: Appl. Phys. Lett., 2009, vol. 94, p. 061901

38. M. Besse, P. Castany, and T. Gloriant: Acta Mater., 2011, vol. 59, pp. 5982-88.

39. M. Abdel-Hady, K. Hinoshita, and M. Morinaga: Scr. Mater., 2006, vol. 55, pp. 477-80.
40. P. Castany, D.M. Gordin, S.I .Drob, C. Vasilecu, and V. Mitran: Shap. Mem. Superelast., 2016, vol. 2, pp. 18-28.

41. S. Handa and O. Izumi: Metall. Tranns. A, 1986, vol. 17, pp. 1409-20.

42. E. Bertrand, P. Castany, I. Peron, and T. Gloriant: Scr. Mater., 2011, vol. 64, pp. 1110-13.

43. S. Sadeghpour, S.M. .Abbasi, M. Morakabati, and L.P. Karjalainen: J. Alloys Compd., 2019, vol. 808, p. 151741.

44. S. Sadeghpour, S.M. Abbasi, M. Morakabati, L.P. Karjalainen, and D.A. Potter: Mater. Sci. Eng. A, 2018, vol. 731, pp. 465-78.

45. S. Liu, Y.Z. Guo, Z.L. Pan, X.Z. Liao, E.J. Lavernia, Y.T. Zhu, Q.M. Wei, and Y. Zhao: J. Mater. Sci. Technol., 2020, vol. 54, pp. 31-39

46. Y. Yiang, G.P. Li, G.M. Cheng, H. Wang, M. Zhang, F. Xu, and K. Yang: Scr. Mater., 2008, vol. 58, p. 9.

47. N. Sakaguch, M. Niinomi, and T. Akahori: Mater. Trans, 2004, vol. 45, p. 1113

48. S. Hanada and O. Izumi: Metall. Trans. A, 1980, vol. 11, p. 1447.

49. S. Hanada, M. Ozeki, and O. Izumi: Metall. Trans. A, 1985, vol. 16, p. 789.

50. S. Hanada and O. Izumi: Metall. Trans. A, 1987, vol. 18, p. 265

51. H. Matsumoto, S. Watanabe, and S. Hanada: Mater. Trans., 2005, vol. 46, pp. 1070-78.

52. H. Matsumoto, S. Watanabe, and S. Hanada: J. Alloys Compd., 2007, vol. 439, pp. 146-55.

53. S. Guo, Q.K. Meng, X.N. Cheng, and X.Q. Zhao: J. Mech. Behav. Biomed. Mater., 2014, vol. 38, pp. 26-32.

54. R.J. Talling, R.J. Dashwood, M. Jackson, S. Kuramoto, and D. Dye: Scripta mater., 2008, vol. 59, p. 669.

55. R.J. Talling, R.J. Dashwood, M. Jackson, and D. Dye: Acta Mater., 2009, vol. 57, p. 1188.

56. H. Xing and J. Sun: Appl. Phys. Lett., 2008, vol. 92, p. 031908.

57. J. Coakley, V.A. Vorontsov, K.C. Littrell, K. Richard, M. Heenan, N. Ohnuma, G. Jones, and D. Dye: J. Alloys and Compd., 2015, vol. 623, pp. 146-56.

58. A. Rusinek and T. Jankowiak: in: Lodygowski T, Rusinek A, editors. Constitutive Relations under Impact Loadings, CISM International Centre for Mechanical Sciences, Vienna, vol. 552. Springer; 2014, pp. 87-135.

59. G.R. Johnson and W.H. Cook: Proceedings of the 7 th International Symposium on Ballistics, The Hauge, 1983, pp. 541-47.

60. R. Liangand and A.S. Khan: Int. J. Plast., 1999, vol. 15, pp. $963-80$.

61. H. Zhan, G. Wang, D. Kent, and M. Dargusch: Mater. Sci. Eng A., 2014, vol. 612, pp. 71-79.

62. L. Niu, M. Cao, Z. Liang, B. Han, and Q. Zhang: Mater. Sci. Eng. $A, 2020$, vol. 789, p. 139612 .

Publisher's Note Springer Nature remains neutral with regard to jurisdictional claims in published maps and institutional affiliations. 